\title{
Primary diffuse large B-cell lymphoma of the dura mater and cranial vault
}

\author{
Case report and review of the literature
}

\author{
Marcelo Galarza, M.D., Roberto Gazzeri, M.D., Hamed A. Elfeky, M.D., AND \\ ROBERT R. JOHNSON II, M.D. \\ Departments of Neurosurgery and Pathology, Sinai Grace Hospital, Detroit, Michigan; and \\ Department of Neurosurgery, Azienda Hospital San Giovanni-Addolorata, Rome, Italy
}

\begin{abstract}
$\checkmark$ Primary high-grade lymphoma of the dura mater and cranial vault has rarely been reported. The authors treated a 61 year-old man who presented with a slow-growing scalp mass that involved the cranial vertex. Magnetic resonance imaging revealed an oval mass of the dural type with peripheral edema in the bilateral parietal region, with attachment to the cranial vault and extension to the subgaleal space. After subtotal resection, pathological examination yielded a diagnosis of malignant large B-cell lymphoma. Twenty-three months postoperatively, after undergoing radiation therapy and chemotherapy, the patient is neurologically intact and without systemic dissemination of the malignancy. This is a case of primary malignant B-cell lymphoma of the dura mater with extensive involvement of the skull, which is a very rare event. Imaging-based diagnosis and combined therapy consisting of surgery, radiation therapy, and chemotherapy for the disease are discussed, and the literature on extraaxial malignant lymphomas is extensively reviewed.
\end{abstract}

\section{KEY WORDS • B-cell lymphoma - extraaxial lymphoma • meninges $・$ cranial vault}

$\mathrm{D}$ IFFUSE large cell, mixed and immunoblastic lymphomas of B-cell origin can be considered together as aggressive lymphomas. Approximately $30 \%$ of cases originate in extranodal sites, particularly the gastrointestinal tract and the Waldeyer ring, but also in bone, skin, sinuses, eyes, ocular adnexa, gonads, the CNS, thyroid, and lungs. $2,8,10,17,23,27,35,37,40$ In unselected series of cases the incidence of primary CNS lymphomas in brain tumors varies from 0.3 to $1 \%$, and the entity constitutes approximately $1 \%$ of all lymphomas. ${ }^{2,17,27,40}$ Within the CNS, these lymphomas have a predilection for the midline or paraventricular structures. Primary extraaxial involvement of large cell type B lymphoma is infrequent, with the worldwide literature containing only a few cases. . $^{910,12,23,35-37,41}$ The precise anatomical location of the neoplasm reported here, without systemic manifestation, makes this case unique in its type.

\section{Case Report}

History and Examination. This 61-year-old man was admitted with generalized headaches, which had developed over a period of 3 months. His medical history was unremarkable. The patient's physical examination demonstrated no focal neurological abnormality other than a palpable biparietal mass involving the scalp. Admission CT

\footnotetext{
Abbreviations used in this paper: $\mathrm{CHOP}=$ cyclophosphamide, doxorubicin, vincristine, and prednisone; $\mathrm{CNS}=$ central nervous system; $\mathrm{CT}=$ computed tomography; $\mathrm{MR}=$ magnetic resonance.
}

scanning revealed a high-density extradural mass in the superior sagittal sinus invading the vertex and subgaleal space that was homogeneously enhanced after contrast administration. In addition, CT scans with bone windows revealed involvement of both cranial tables without osteolysis. No cerebral edema was in evidence. On MR imaging, the mass measured $13 \times 8 \times 2 \mathrm{~cm}$. It was slightly hypointense on $\mathrm{T}_{1}$-weighted and hyperintense to gray matter on $\mathrm{T}_{2}$-weighted images. Tumor enhancement after administration of gadolinium was homogeneous. Associated swelling of the pericranium and subcutaneous tissue involvement were observed (Fig. 1). Downward displacement of a patent superior sagittal sinus was present. Based on the location of the lesion, precontrast signal intensities, and an additional lesion outside the cranium, a metastatic tumor rather than a typical meningioma was suspected.

Operation. The large excrescent mass was resected through a right parietal craniotomy with contralateral extension. The tumor was gray, firm, relatively avascular, and densely attached to the dura mater from which it arose. The adjacent bone was severely infiltrated in both cranial tables, with continuous infiltration of the galea and subcutaneous fatty tissue. Our diagnosis (based on evaluation of frozen sections) was poorly differentiated malignant neoplasm that we strongly suspected was a lymphoma.

Postoperative Course. The patient's postoperative course was uneventful and he recovered completely. Results of a radiographic skeletal survey were negative. Follow-up CT 

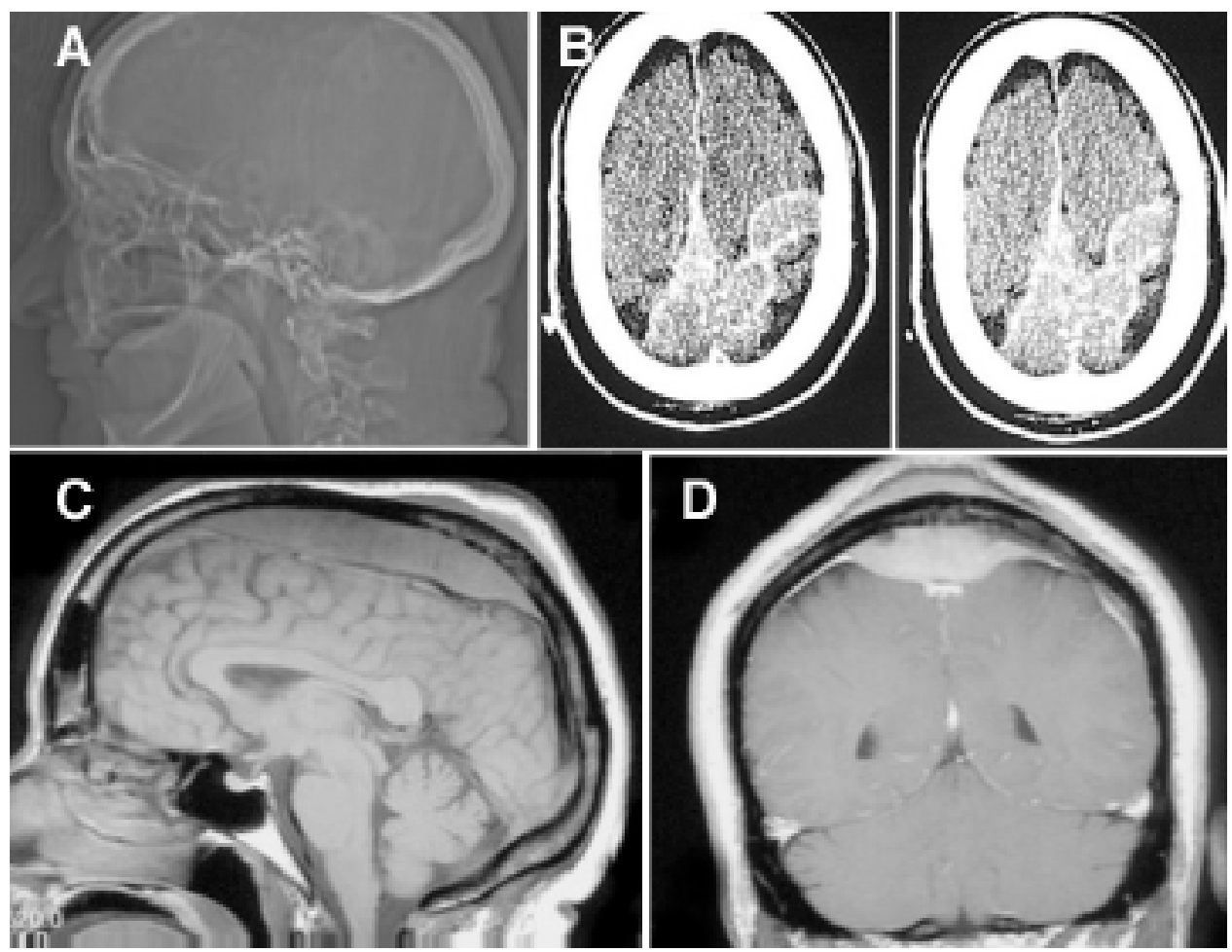

FIG. 1. Sagittal scout view (A) revealing no evidence of lytic or blastic lesions in the cranial vault. Head CT scans (B) obtained without addition of contrast material, demonstrating an extraaxial bilateral frontoparietal lesion involving the cerebral falx and meninges. Sagittal and coronal T1-weighted MR images obtained without (C) and with (D) gadolinium contrast, demonstrating a contrast-enhanced (in D), transcalvarial mass that permeates the diploic space and occupies the subgaleal space.

scanning of the chest, abdomen, and pelvis demonstrated no evidence of pathological entities. Assessment of a bone marrow aspirate yielded normal results.

Pathological Findings. On microscopic examination, the neoplasm was seen to be composed of atypical, moderately large, mitotically active, occasionally cleaved, pleomorphic lymphoid cells. The neoplastic cells were infiltrating and destroying osseous tissue. Tumor immunophenotyping was done using flow cytometric analysis (CD5, CD10, CD19, and CD20) and by histochemical evaluation of the lymphoid cells. These exhibited strong immunoreactivity both to leukocyte common antigen and to B-cell marker (L26). The nuclear staining proliferation index with $\mathrm{Ki} 67$ (MIB-1 marker) exceeded $90 \%$ of tumor cells. No staining was noted for chromogranin, synaptophysin, or the epithelial markers AE1 and AE3. The final neuropathological report confirmed the diagnosis of a high-grade meningeal diffuse large B-cell lymphoma with extensive involvement of a marginal zone (Fig. 2).

Adjuvant Therapy and Outcome. After the pathological findings were reviewed, the patient was treated with $\mathrm{CHOP}$ chemotherapy every 3 weeks for six cycles. After that, fractionated whole-brain radiation therapy was delivered in 18 fractions of $180 \mathrm{cGy}$ each. After treatment, the patient remained free of neurological symptoms. Head CT scans and MR images obtained 4 months after surgery and adjuvant therapy revealed no residual tumor. After a follow-up duration of 23 months, the patient is neurologically intact and has no systemic dissemination of the malignancy.

\section{Discussion}

The medical literature offers a wide variety of reported cases of extraaxial primary CNS lymphomas. Neverthe-

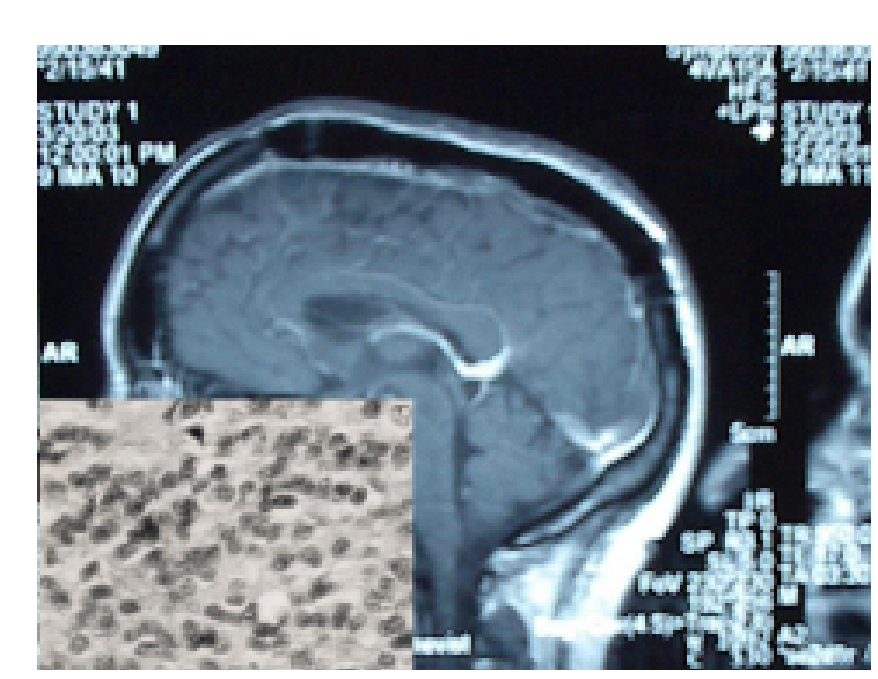

FIG. 2. Postoperative sagittal $\mathrm{T}_{1}$--weighted MR image obtained after gadolinium administration demonstrating complete resection of the lesion. Inset: High-power photomicrograph showing the neuropathological features of a primary diffuse large B-cell lymphoma of the meninges and cranial vault. Large bizarre lymphoid cells can be seen in the right lower quadrant. H \& E, original magnification $\times 40$. 
Primary B-cell dural lymphoma

TABLE 1

Literature review of primary meningeal high-grade B-cell lymphomas*

\begin{tabular}{|c|c|c|c|c|c|}
\hline Authors \& Year & Patient Age (yrs), Sex & Location of Lesion & Cranial Vault Involvement & Symptoms & Postop Treatment \\
\hline Holtas, et al., 1985 & 60, F (Case 1) & lt frontal & yes & seizures, scalp mass & RT \\
\hline Parekh, et al., 1993 & $65, \mathrm{~F}$ & lt parietal & yes & scalp lump & RT \\
\hline Sato, et al., 1993 & $65, \mathrm{M}$ & rt parietal & yes & scalp mass, hemiparesis & RT \& chemo \\
\hline Landys, et al., 1995 & $62, \mathrm{M}$ & frontoparietal & yes & headaches & chemo \\
\hline \multirow[t]{2}{*}{ Paige \& Bernstein, 1995} & $51, \mathrm{M}$ & bilat occipital & yes & scalp mass, headaches & chemo \& RT \\
\hline & $71, \mathrm{M}$ & lt temporal & & & \\
\hline Curty, et al., 1997 & $19, \mathrm{M}$ & rt parietal & yes & scalp lump, headaches & chemo \\
\hline Freudenstein, et al., 2000 & $50, \mathrm{~F}$ & bilat convexity & no & headaches, seizures & RT \& chemo \\
\hline Pardhanani, et al., 2000 & 77, M & lt orbitofrontal & yes & ocular proptosis & RT \\
\hline
\end{tabular}

$*$ Chemo $=$ chemotherapy; $\mathrm{RT}=$ radiation therapy.

less, after meticulous analysis of the reported cases (Table 1 ), we found that there are only a few with characteristics similar to the one reported here. Other reported cases included the following: 1) a similar type of lymphoma but in other extraaxial locations (that is, orbit, ${ }^{35}$ Meckel cave, ${ }^{1,5}$ parasellar, ${ }^{34,40}$ zygoma, ${ }^{32,35}$ or cerebellopontine angle, $\left.{ }^{8}\right)$; 2) a different subtype of lymphoma according to the clinical classification of non-Hodgkin lymphomas ${ }^{2}$ (that is, Tcell, ${ }^{28,29}$ mixed type, ${ }^{4,11,22}$ noncleaved, ${ }^{11,26,39}$ small cell type, $3,12,21,33,38$ and low-grade [including mucosa-associated lymphoid tissue lymphomas] $)^{14,19,20,24}$; 3) other extraaxial lymphoid tumors; $6,7,13,15,18,30,42$ and 4) nonspecified types of lymphomas in the reported cases. . $^{16,25,31,40}$

Lymphomas involving the skull may imitate meningiomas, ${ }^{3,4}$ metastases, ${ }^{29}$ or, less frequently, extradural abscesses with osteomyelitis ${ }^{12,35}$ or extradural hematomas. ${ }^{39}$ High-grade lymphomas involving bone are characterized by a permeative growth pattern and a large soft-tissue component in the extradural and galeal compartment; nonetheless, there may be limited destruction of cortical bone, as in the present case. Periosteal reaction is occasionally seen, especially when a soft-tissue mass is present. Metastatic carcinomas in the extraaxial CNS may show osteolytic bone lesions. Patients with chronic osteomyelitis usually demonstrate lytic bone lesions and systemic signs. ${ }^{12,35,37}$ The most likely alternative entity to rule out is noncalcified meningioma, for which angiography is usually diagnostic. Meningiomas demonstrate a distinct pattern of contrast enhancement, and may have associated hyperostosis or calcifications.,12,17,41 The angiographic finding typical of lymphoma is an avascular tumor. A blush or vascular encasement of the mass seems to be rare. ${ }^{16}$ In our case, as in previous reports, malignant dural lymphomas with extensive involvement of the cranial vault revealed a nonhomogeneous hyperdensity on MR imaging, lack of calcifications on CT scanning, and dim contrast enhancement on both imaging modalities.

Therapy for intermediate- to high-grade non-Hodgkin lymphomas in localized extranodal presentations of less than $10 \mathrm{~cm}$ can be successfully managed by three cycles of an adriamycin-containing regimen (CHOP protocol) followed by radiation therapy in the involved field. Other approaches include a full course of aggressive chemotherapy with or without subsequent radiation therapy, and radiation therapy alone in carefully selected cases. ${ }^{2}$ In our case, the tumor seems to be controlled with the aforementioned combination therapy.

\section{Conclusions}

Although it is extremely uncommon, primary malignant lymphoma should be considered in the differential diagnosis of scalp masses. This is especially true when a mass involves both dura mater and cranial bone, the patient has a painless clinical presentation, and the aforesaid imaging characteristics are observed. Nonetheless, the number of occurrences of this entity reported in the literature is too small to allow consideration of final conclusions.

\section{References}

1. Abdel Aziz KM, van Loveren HR: Primary lymphoma of Meckel's cave mimicking trigeminal schwannoma: case report. Neurosurgery 44:859-863, 1999

2. Abrey LE, Yahalom J, DeAngelis LM: Treatment for primary CNS lymphoma: the next step. J Clin Oncol 18:3144-3150, 2000

3. Agbi CB, Bannister CM, Turnbull IW: Primary cranial vault lymphoma mimicking meningioma. Neurochirurgia (Stuttg) 26:130-132, 1983

4. Amaker BH, Ghatak NR, Jebraili SA, Ferreira-Gonzalez A, Kornstein MJ: Primary T-cell-rich B-cell lymphoma masquerading as a meningioma. Arch Pathol Lab Med 124: 1700-1703, 2000

5. Artico M, Salvati M, Raco A, Innocenzi G, Delfini R: [Primary Meckel's cave lymphoma. A case and review of the literature.] Neurochirurgie 38:368-371, 1992 (Fr)

6. Aslan Y, Okten A, Demirci A: Primary Burkitt's lymphoma of the cranial vault in a child. Pediatr Radiol (1 Suppl) 25: 232-233, 1995

7. Benli K, Inci S: Solitary dural plasmacytoma: case report. Neurosurgery 36:1206-1209, 1995

8. Berciano J, Jimenez C, Figols J, Ferreres JC, Combarros O, Arjona R, et al: Primary leptomeningeal lymphoma presenting as cerebellopontine angle lesion. Neuroradiology 36:369-371, 1994

9. Curty B, Kernan J, Favre J: Malignant non-Hodgkin's lymphoma of the cranial vault: a case report. Br J Neurosurg 11: 433-436, 1997

10. Freudenstein D, Bornemann A, Ernemann U, Boldt R, Duffner F: Intracranial malignant B-cell lymphoma of the dura. Clin Neuropathol 19:34-37, 2000

11. Herkes GK, Partington MD, O'Neill BP: Neurological features of cranial vault lymphomas: report of two cases. Neurosurgery 29:898-901, 1991

12. Holtas S, Monjati A, Utz R: Computed tomography of malignant lymphoma involving the skull. J Comput Assist Tomogr 9:725-727, 1985

13. Hsiang JN, Ng HK, Poon WS. Atypical monoclonal plasma cell 
hyperplasia: its identity and treatment. Case report. J Neurosurg 85:697-700, 1996

14. Isla A, Alvarez F, Gutierrez M, Gamallo C, Garcia-Blazquez M, Vega A: Primary cranial vault lymphoma mimicking meningioma. Neuroradiology 38:211-213, 1996

15. Jakubowski J, Kendall BE, Symon L: Primary plasmocytomas of the cranial vault Acta Neurochir (Wein) 55:117-134, 1980

16. Jamjoom AB, Jamjoom ZA, Naim-Ur-Rahman, Cheema MA: Primary midline cranial vault lymphoma simulating a parasagittal meningioma: the role of angiography in preoperative diagnosis. Neurosurg Rev 21:202-205, 1998

17. Jiddane M, Nicoli F, Diaz P, Bergvall U, Vincentelli F, Hassoun $\mathrm{J}$, et al: Intracranial malignant lymphoma: Report of 30 cases and review of the literature. J Neurosurg 65:592-599, 1986

18. Johnson MD, Kinney MC, Scheithauer BW, Briley RJ, Hamilton K, McPherson WF, et al: Primary intracerebral Hodgkin's disease mimicking meningioma: case report. Neurosurgery 47:454-457, 2000

19. Kambham N, Chang Y, Matsushima AY: Primary low-grade Bcell lymphoma of mucosa-associated lymphoid tissue (MALT) arising in dura. Clin Neuropathol 17:311-317, 1998

20. King A, Wilson H, Penney C, Michael W: An unusual case of primary leptomeningeal marginal zone B-cell lymphoma. Clin Neuropathol 17:326-329, 1998

21. Kinjo T, Satoh T: [A case of malignant lymphoma of the skull after head injury associated with multiple bone tumors.] No Shinkei Geka 13:1191-1196, 1985 (Jap)

22. Kumon Y, Sakaki S, Nakano K, Fukui K, Kohno H, Kurihara $\mathrm{K}$ : [Primary malignant lymphoma of the skull presenting as a growing mass in the forehead; a case report.] No Shinkei Geka 19:279-283, 1991 (Jap)

23. Landys KE, Berg GE, Torgerson JS, Klingenstierna HA, Ridell BS, Johansson BR: Bulky centroblastic non-Hodgkin's lymphoma of the cranium vault mimicking brain involvement managed with chemotherapy: a case report. Cancer 76:1261-1267, 1995

24. Lehman NL, Horoupian DS, Warnke RA, Sundram UN, Peterson K, Harsh GR IV: Dural marginal zone lymphoma with massive amyloid deposition: rare low-grade primary central nervous system B-cell lymphoma. Case report. J Neurosurg 96:368-372, 2002

25. Loembe PM, Minko-Mi-Etoua D, Mekemeza-M'Obiang L, Assengone-Zeh Y, Mwanyombet-Ompounga L: Primary lymphoma of frontoparietal localization in the cranial vault. Report of a case. Neurochirurgie 40:369-371, 1994 (Fr)

26. Lonjon M, Hofman P, Thyss A, Paquis P, Roche JL: [Primary lymphoma of the cranial vault. Apropos of a case.] Neurochirurgie 39:50-53, 1993 (Fr)

27. Lyons MK, O'Neill BP, Marsh WR, Kurtin PJ: Primary spinal epidural non-Hodgkin's lymphoma: report of eight patients and review of the literature. Neurosurgery 30:675-680, 1992
28. Mauri F, Corriero G, Giamundo A: Primary lymphoma of the cranial vault. J Neurosurg Sci 31:183-186, 1987

29. Morgello S, Maiese K, Petit CK: T-cell lymphoma in the CNS: clinical and pathological features. Neurology 39:1190-1196, 1989

30. Nagashima K, Mori S, Yoshimasu N, Takahashi K: Primary Hodgkin's disease of the falx cerebri. Acta Neuropathol 51: $161-163,1980$

31. Narberhaus B, Buxo J, Perez de Olaguer J, Forcadas P, GarciaBach M, Aparicio A, et al: [Primary dural lymphoma.] Neurologia 11:117-119, 1996 (Span)

32. Ng YY, Cook JA, McRae RD: Lymphoma of the zygoma: an unusual cause of unilateral facial swelling. J Otolaryngol 19: 315-318, 1990

33. Nguyen D, Nathwani BN: Primary meningeal small lymphocytic lymphoma. Am J Surg Pathol 13:67-70, 1989

34. Oyama H, Nagane M, Shibui S, Nomura K, Mukai K: Skull base malignant lymphoma: a case report and review of the literature. Jpn J Clin Oncol 22:131-135, 1992

35. Paige ML, Bernstein JR: Transcalvarial primary lymphoma of bone. A report of two cases. Neuroradiology 37:456-458, 1995

36. Pardhanani G, Ashkan K, Mendoza N: Primary non-Hodgkin's lymphoma of the cranial vault presenting with unilateral proptosis. Acta Neurochir (Wien) 142:597-598, 2000

37. Parekh HC, Sharma RR, Keogh AJ, Prabhu SS: Primary malignant non-Hodgkin's lymphoma of cranial vault: a case report. Surg Neurol 39:286-289, 1993

38. Pernot P, Saint-Blancard P, Dulou R, Blondet E, Goasguen O: [Primary dural lymphoma. A case report.] Neurochirurgie 48: 124-127, 2002 (Fr)

39. Rabin DN, Ramsey RG, Vedanthum KS, Foust RJ, Rabin M: Extradural lymphoma presenting as an acute surgical emergency. Neurosurgery 20:788-790, 1987

40. Roman-Goldstein SM, Jones A, Delashaw JB, McMenomey S, Neuwelt EA: Atypical central nervous system lymphoma at the cranial base: report of four cases. Neurosurgery 43:613-616, 1998

41. Sato M, Saito T, Yamaguchi K: [Primary malignant lymphoma of the skull presenting a huge mass lesion: case report.] No Shinkei Geka 21:1061-1064, 1993 (Jap)

42. Vigushin DM, Hawkins PN, Hsuan JJ, Totty NF, Pepys MB: AL kappa amyloid in a solitary extradural lymphoma. J Neurol Neurosurg Psychiatry 57:751-754, 1994

Manuscript received August 8, 2006.

Accepted in final form October 4, 2006.

Address reprint requests to: Marcelo Galarza, M.D, Division of Neurosurgery, Villa Maria Cecilia Hospital, 48010, Cotignola, Rome, Italy. email: galarza.marcelo@gmail.com. 